\title{
Effects of one single bout of low-intensity exercise on postprandial lipaemia in type 2 diabetic men
}

\author{
Marian Dalgaard*, Claus Thomsen and Kjeld Hermansen \\ Department of Endocrinology and Metabolism, Aarhus University Hospital, Tage-Hansens Gade 2, DK-8000 Aarhus C, \\ Denmark
}

(Received 28 August 2003 - Revised 10 May 2004 - Accepted 25 May 2004)

\begin{abstract}
Fighting type 2 diabetes and its high risk of CVD, lifestyle intervention with diet and exercise is of uttermost importance. Epidemiological studies strongly suggest an inverse association between increased physical activity, moderate alcohol drinking and the incidence of both type 2 diabetes and CVD. However, alcohol is known to increase postprandial lipaemia, a risk marker of CVD, and exercise to reduce postprandial lipaemia in healthy individuals. The aim of the present study was to investigate how type 2 diabetic men respond, in the postprandial period, to a single exercise session feasible to perform on a daily basis for type 2 diabetic men. The twelve participants ingested a test meal containing $100 \mathrm{~g}$ butter, $50 \mathrm{~g}$ carbohydrate, together with $40 \mathrm{~g}$ alcohol, at each meal test, imitating a social meal situation. Two protocols included exercise sessions with $40 \mathrm{~min}$ at $40 \% \mathrm{~V}_{\mathrm{O} 2 \mathrm{max}}$, one where they exercised $3.5 \mathrm{~h}$ after, and another the afternoon before the test meal. One protocol was without any exercise. No significant effect of low-intensity exercise on postprandial lipaemia following a fat-rich meal with alcohol was seen in the middle-aged type 2 diabetic men.
\end{abstract}

Exercise: Physical activity: Diabetes mellitus: Postprandial lipaemia: Ethanol

Type 2 diabetes is characterised by insulin resistance, and is associated with a breakdown of lipid homeostasis reflected by elevated levels of circulating NEFA and triacylglycerols in the fasting and postprandial period, low HDL-cholesterol and a preponderance of small, dense LDL. All these factors contribute to an increased risk of CVD in type 2 diabetes (Fraze et al. 1985; Chen et al. 1993; Isomaa et al. 2001; Taskinen, 2003). Exaggerated postprandial lipaemia has been linked to arteriosclerosis (Patsch et al. 1992; Ryu et al. 1992; Boquist et al. 1999; Karpe, 1999). The exaggerated triacylglycerol response in type 2 diabetes seems partly to derive from an increased substrate delivery of NEFA and glycerol from the adipose tissue to the liver and an increased hepatic secretion of VLDL particles due to extrahepatic and hepatic insulin resistance (Malmstrom et al. 1997). In addition to fasting triacylglycerol levels, diet, current smoking and alcohol consumption have been shown to influence postprandial lipid responses (Parks, 2001; Sharrett et al. 2001; Thomsen et al. 2003).

Alcohol in moderate amounts also seems to have a beneficial effect on the risk of developing both type 2 diabetes and CVD. The Health Professionals' follow-up study showed that the regular intake of moderate alcohol amounts is associated with a reduced relative risk of developing type 2 diabetes by $50 \%$ (Conigrave et al. 2001). Also, drinking on at least 3 or $4 \mathrm{~d} /$ week is associated with a decrease in the relative risk of myocardial infarction by $37 \%$ (Mukamal et al. 2003). The relative risk of cardiovascular heart disease in type 2 diabetic men who consumed alcohol was reduced by $40 \%$ compared with non-drinkers (Tanasescu et al. 2001).

Despite the cardioprotective effect observed in largescale epidemiological studies, it is well known that acute alcohol intake increases postprandial lipaemia in healthy individuals (Veenstra et al. 1990; Pownall, 1994; van Tol et al. 1995; Hendriks et al. 1998; Fielding et al. 2000).

Regular physical activity is an important lifestyle factor associated with a reduced incidence of both CVD and type 2 diabetes. Bicycling to work is associated with a reduction in mortality (Andersen et al. 2000), and physical activity for $30 \mathrm{~min}$ or more on a daily basis compared with $0 \mathrm{~min}$ has been shown to reduce the relative risk of type 2 diabetes by $36 \%$ (Hu et al. 2003). Type 2 diabetic women who engaged in moderate exercise for $4 \mathrm{~h}$ or more/week had a relative risk of a cardiovascular event of 0.55 compared with diabetic women who exercised for less than $1 \mathrm{~h} /$ week (Hu et al. 2001). Also, the relative risk of CVD in type 2 diabetic men with low fitness was found to be twice that of fit diabetic men (Wei et al. 2000). Some investigators have shown that one single bout of exercise less than $24 \mathrm{~h}$ before a meal can reduce postprandial lipaemia (Schlierf et al. 1987; Tsetsonis \& Hardman, 1996; Tsetsonis et al. 1997; Gill et al. 2002; Petitt et al. 2003). Few studies have compared how exercise influences postprandial lipaemia in response to alcohol intake (Hartung et al. 1993; Rasmussen et al. 1999; El Sayed \& AL-Bayatti, 2001; Suter et al. 2001).

\footnotetext{
Abbreviations: AUC, area under the curve; iAUC, incremental area under the curve.

* Corresponding author: Dr Marian Dalgaard, fax +45 86193807, email mad@dadlnet.dk
} 
Most of the literature concerning postprandial lipaemia and exercise includes healthy individuals engaged in moderate exercise for long periods (Petitt \& Cureton, 2003). Little is known about the influence of low-intensity exercise and alcohol on postprandial lipaemia in diabetic individuals, which is of relevance to describe in relation to future health recommendations regarding exercise and alcohol intake. The objective of the present study was to determine the acute effects of an exercise stimulus that would be realistic to perform on a daily basis on the postprandial responses in type 2 diabetic men when their metabolic system was challenged by alcohol and fat.

\section{Subjects and methods}

\section{Study group}

Fourteen type 2 diabetic men were included in the present study; two participants left the study, because of their job situation. The mean duration of type 2 diabetes for the participants was 3.3 (SD 2.2) years. The mean age of the twelve participants was 59.3 (SD 10.4) years, BMI 27.9 (SD 2.8$) \mathrm{kg} / \mathrm{m}^{2}$, and waist circumference 1040 (SD 59) mm. The screening level of $\mathrm{HbA}_{1 \mathrm{c}}$ was 7.2 (SD 1.3) \%; the fasting triacylglycerol level was 2.8 (SD 2.0) $\mathrm{mmol} / \mathrm{l}$. The mean $\mathrm{V}_{\mathrm{O} 2 \mathrm{max}}$ was low (28 (SD 6) $\mathrm{ml} / \mathrm{kg}$ per min). With the exception of four participants receiving sulfonylurea, the participants did not receive anti-diabetic drugs. The participants continued their regular medication during the whole study. All participants consumed alcohol on a weekly basis with a range of average weekly intake of three to thirty-five drinks (one drink containing $12 \mathrm{~g}$ alcohol). Three were smokers, smoking twenty cigarettes/d.

The participants were selected from outpatients of the diabetes clinic at Aarhus University Hospital, Aarhus, Denmark. The local ethics committee of Aarhus County approved the study protocol. The subjects were fully informed of the experimental nature of the study and gave their written, informed consent to participate. Inclusion criteria were: men with type 2 diabetes for more than 1 year, diagnosed by their general practitioner or at the hospital. Exclusion criteria included: uncontrolled diseases, severe heart disease (New York Heart Association classification 3 or 4 ) or renal insufficiency (blood creatinine over $150 \mu \mathrm{mol} / \mathrm{l}$ ) or treatment with insulin, $\beta$-blockers or lipid-lowering medication.

\section{Exercise}

At the screening visit a sub-maximal exercise test, using the Åstrand (1960) protocol, with continuous monitoring of the heart rate was performed on a bicycle ergometer (Monark Electronic Ergometer 829 E; Monark Exercise, Varberg, Sweden). The workload, in conjunction with the resultant heart rate, was compared with the predicted relationship, adjusted for age and sex, and the $\mathrm{V}_{\mathrm{O} 2 \max }$ was computed. The steady-state heart rate during the last 2 min of work was used for the calculation of $\mathrm{V}_{\mathrm{O} 2 \max }$. In a comparable group the indirect measures of $\mathrm{V}_{\mathrm{O} 2 \max }$ have been shown to correlate well with $\mathrm{V}_{\mathrm{O} 2 \max }$ determined by direct measurements, with a CV of less than $10 \%$ (Lindgarde \& Saltin,
1981; Berntorp et al. 1986). In protocols B and C (see later) the participants exercised at $40 \% \mathrm{~V}_{\mathrm{O} 2 \max }$ for $20 \mathrm{~min}$ followed by $20 \mathrm{~min}$ rest before the last $20 \mathrm{~min}$ of exercise. The workload during exercise ranged from 32.7 to 89.9 W. Mean workload was 59 (SD 21) W. We did not measure heart rate continuously during the exercise sessions.

\section{Design}

The study consisted of three protocols, A, B and C, each carried out on separate days with at least 1 week apart (FIg. 1). The participants took part on an outpatient basis in random order in the present cross-over study, each participant serving as his control. Each protocol started at 08.00 hours the day before a meal test and ended at 08.00 hours the morning after a meal test, i.e. a total of $48 \mathrm{~h}$. During the initial $24 \mathrm{~h}$ of each protocol (day 1) the participants ingested food delivered by the dietitian. The level of physical activity during the initial $24 \mathrm{~h}$ differed between the protocols. On the second day of each protocol basal fasting blood samples and postprandial responses to a fat-rich test meal and different levels of physical activity were measured. Each protocol ended on the third morning at 08.00 hours on which final fasting blood samples were taken. In protocol A, participants rested both during day 1 and day 2 (control). In protocol $\mathrm{B}$, participants rested during day one and exercised $3.5 \mathrm{~h}$ after the test meal. In test protocol $\mathrm{C}$, participants exercised on the afternoon on day 1 , and rested on day 2 .

\section{Interventions}

Nutritional supplement. The participants ingested a highcarbohydrate diet delivered by the dietitian, with an energy distribution of $50 \%$ carbohydrate, $32 \%$ fat and $18 \%$ protein on the first day of each protocol. The food amount corresponded to individual energy requirements estimated by the Harris-Benedict equation with adjustment for activity (Pellett, 1990). After the meal test, a meal was served at the investigation site and a food pack for the rest of the day was delivered ensuring that total energy ingested on day 2 was similar to the energy ingested on day 1; however, the energy distribution was not similar due to the high content of fat in the test meal.

Test conditions. At each meal test the same meal with alcohol was served at $\mathrm{T}=0 \mathrm{~min}$. The meal consisted of an energy-free soup with $100 \mathrm{~g}$ butter ( $80 \mathrm{~g}$ fat) plus $40 \mathrm{~g}$ alcohol and $50 \mathrm{~g}$ carbohydrate as white bread. The meal contained mainly saturated fatty acids ( $72 \%$ of total fat). The soup was chilled briefly and then butter was added. Sliced raw leek was added to give taste. The meal test ended at $\mathrm{T}=480 \mathrm{~min}$. The morning after each meal test, the participants arrived after an $11 \mathrm{~h}$ fast and delivered fasting blood samples $(\mathrm{T}=1440 \mathrm{~min})$.

Exercise sessions. No exercise was performed in protocol A. Exercise in $2 \times 20 \mathrm{~min}$ at $40 \% \mathrm{~V}_{\mathrm{O} 2 \max }$ was performed $210 \pm 21 \mathrm{~min}$ after $\mathrm{T}=0$ in protocol $\mathrm{B}$, and in protocol $\mathrm{C}$ the same amount of exercise was performed during the afternoon about $16 \mathrm{~h}$ before $\mathrm{T}=0$.

The participants were instructed to standardise and minimise their physical activity $3 \mathrm{~d}$ before the protocols started. 


\begin{tabular}{|c|c|c|c|c|c|c|}
\hline 08.00 hours & 20.00 hours & $\begin{array}{l}(T=0 \mathrm{~min}) \\
08.00 \text { hours }\end{array}$ & $\begin{array}{l}(T=480 \mathrm{mir} \\
16.00 \text { hours }\end{array}$ & & 20.00 hours & $\begin{array}{l}(T=1440 \mathrm{~min}) \\
08.00 \text { hours }\end{array}$ \\
\hline$\downarrow$ & $\boldsymbol{\nabla}$ & $\nabla$ & $\nabla$ & & $\downarrow$ & $\downarrow$ \\
\hline $\begin{array}{l}\text { Normal daily activity } \\
\text { High-carbohydrate food } \\
\text { delivered by dietitian }\end{array}$ & Fasting & Start of meal test & $\begin{array}{l}\text { End of } \\
\text { meal test }\end{array}$ & $\begin{array}{l}\text { Food } \\
\text { pack } \\
\text { delivered } \\
\text { by dietitian }\end{array}$ & Fasting & $\begin{array}{l}\text { Fasting } \\
\text { blood sample }\end{array}$ \\
\hline
\end{tabular}

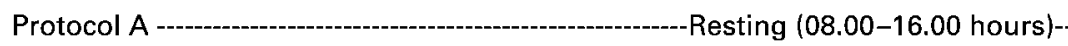

Protocol $B$ -
$\left(40 \min 40 \% V_{02 \max }\right)$

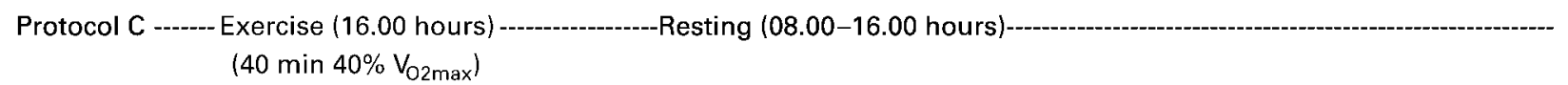

Fig. 1. Study flow chart. Test meal of soup with $100 \mathrm{~g}$ butter plus $40 \mathrm{~g}$ alcohol plus $50 \mathrm{~g}$ carbohydrate.

No alcohol drinking or heavy physical work was allowed $24 \mathrm{~h}$ preceding each protocol. No smoking or intake of medication was allowed from day 1 in the protocols. On the second day, following an $11 \mathrm{~h}$ fast, the subjects arrived between 07.00 and 07.30 hours using a minimum of physical activity. Subsequently a catheter was placed in an antecubital vein and basal blood samples were drawn $15 \mathrm{~min}$ later (baseline period). The meal test started at $\mathrm{T}=0 \mathrm{~min}$ and the meal was ingested during a 20 min period. The participants were allowed to walk freely in the ward during the meal test. Blood samples were drawn every $1 \mathrm{~h}$ the first $4 \mathrm{~h}$ and thereafter at $\mathrm{T}=360 \mathrm{~min}$ and $\mathrm{T}=480 \mathrm{~min}$ for analysis of glucose, insulin, fatty acids, triacylglycerol, total cholesterol and HDL-cholesterol. Plasma was immediately separated by centrifugation at $2000 \mathrm{~g}$ for $20 \mathrm{~min}$ at $4^{\circ} \mathrm{C}$ and kept frozen at $-20^{\circ} \mathrm{C}$ until analysed.

\section{Bioanalysis}

Plasma glucose was measured by a glucose oxidase method (CV 3.8\%) (MPR 3166391 glucose/GOD-PAP method; Boehringer Mannheim, Mannheim, Germany) (Trinder, 1969). Serum insulin concentrations were measured by an ELISA method (CV 1.7\%) (Andersen et al. 1993). Serum triacylglycerols (CV 2.05\%), serum cholesterol (CV 1.9\%), serum HDL-cholesterol (CV 3.9\%) (code no. 701912, 2016630, 543004, respectively; Roche Diagnostics $\mathrm{GmbH}$, Mannheim, Germany), and serum fatty acids (CV 1.1\%) were measured with standard enzymic colorimetric assays by using commercial kits (code no. 994-75409; Wako Chemicals GmbH, Neuss, Germany).

\section{Statistical analysis}

Results are expressed as mean values and standard deviations of individually analysed data for the twelve participants. For paired comparisons between fasting values, area under the curve (AUC), incremental AUC (iAUC) and oneway repeated measures of ANOVA were used. Whenever data were not normally distributed, the Friedman repeated measures ANOVA on ranks was used. In case of statistical differences between these groups, a Student-NewmanKeuls post hoc test was used. Significance was assessed by two-tailed tests (SigmaStat version 2.03; BMDP Statistical Software, Berkeley, CA, USA). $P<0.05$ was considered statistically significant. The trapezoidal rule was used to calculate the AUC and iAUC for glucose, insulin, NEFA, total and HDL-cholesterol and triacylglycerol. The iAUC is calculated from the summation of the mean concentration for each time period after subtraction of the mean basal value, multiplied by the number of minutes in the time period. Values below baseline were calculated as negative. The iAUC derived expresses both the duration and the magnitude of the responses, while correcting for baseline values. Insulin sensitivity was calculated, for each of the three protocols, by the homeostasis model assessment model for the fasting values at $\mathrm{T}=0 \mathrm{~min}$ and $\mathrm{T}=1440 \mathrm{~min}$ (Matthews et al. 1985; Haffner et al. 1996). Insulin resistance was calculated as follows:

$$
\begin{aligned}
\text { Insulin resistance }= & (\text { fasting insulin }(\mu \mathrm{U} / \mathrm{ml}) \\
& \times \text { fasting glucose }(\mathrm{mmol} / \mathrm{l})) / 22 \cdot 5 .
\end{aligned}
$$

\section{Results}

Basal values, areas under the curve and incremental areas under the curve

Twelve type 2 diabetic men completed the present study. Weight decreased slightly during the study period from $91.6(\mathrm{SD} \mathrm{12.2)}$ ) to $90.8(\mathrm{SD} \mathrm{12.3)} \mathrm{kg}$ at the end of the study $(P=0.045)$.

No differences between fasting values at $\mathrm{T}=0$ for each of the three protocols (Table 1) were seen except for the 
Table 1. Basal fasting glucose, insulin and lipids in twelve type 2 diabetic men for each of the protocols* (Mean values and standard deviations)

\begin{tabular}{|c|c|c|c|c|c|c|c|}
\hline & \multicolumn{2}{|c|}{ Protocol A } & \multicolumn{2}{|c|}{ Protocol B } & \multicolumn{2}{|c|}{ Protocol C } & \multirow{2}{*}{$\begin{array}{c}P \text { value } \\
\text { (comparisons between protocols) }\end{array}$} \\
\hline & Mean & SD & Mean & SD & Mean & SD & \\
\hline Plasma glucose (mmol/l) & $9 \cdot 3$ & $2 \cdot 7$ & 8.9 & $2 \cdot 0$ & $9 \cdot 2$ & $2 \cdot 4$ & 0.92 \\
\hline Serum insulin $(\mathrm{pmol} / \mathrm{l})$ & $43 \cdot 1$ & 35.5 & $45 \cdot 2$ & 37.5 & $49 \cdot 4$ & $49 \cdot 9$ & 0.53 \\
\hline Serum triacylglycerol (mmol/l) & $2 \cdot 6$ & 1.6 & $2 \cdot 4$ & 1.6 & $2 \cdot 7$ & 2.5 & $0 \cdot 21$ \\
\hline Serum NEFA $(\mathrm{mmol} / \mathrm{l})$ & 0.7 & $0 \cdot 2$ & 0.7 & 0.2 & 0.7 & $0 \cdot 2$ & 0.57 \\
\hline Serum cholesterol (mmol/l) & $6 \cdot 0$ & 1.0 & $5 \cdot 7$ & 0.7 & 5.9 & 0.9 & 0.25 \\
\hline
\end{tabular}

${ }^{a, b}$ Mean values within a row with unlike superscript letters were significantly different $(P=0.02)$

* In protocol A, participants did not exercise; in protocol B, participants rested the day before the meal test and exercised for 40 min at $40 \% V_{O 2 m a x}$ on the day of the meal test; in protocol $\mathrm{C}$, patients exercised for $40 \mathrm{~min}$ at $40 \% \mathrm{~V}_{\mathrm{O} 2 \mathrm{max}}$ the day before the meal test.

lower values of HDL-cholesterol for protocol B compared with protocol A (Table 1).

Triacylglycerols. No significant differences between the three protocols were detected (Tables 1,2 and 3). Triacylglycerol levels after $8 \mathrm{~h}$ were increased by about $75 \%$ compared with the fasting values (FIg. 2).

Non-esterified fatty acids. No differences between protocols were observed for NEFA (Tables 1, 2 and 3).

Cholesterol responses. Fasting HDL-cholesterol was higher at $\mathrm{T}=0$ in protocol $\mathrm{A}$ compared with protocol $\mathrm{B}$ (Table 1). No significant differences in AUC or iAUC for total cholesterol or HDL-cholesterol between the three protocols were detected (Tables 2 and 3).
Glucose, insulin and insulin sensitivity. No significant differences in iAUC of glucose and insulin between the three protocols were detected (Table 2). The AUC for insulin on meal test $\mathrm{C}$ was significantly higher than the two other days (Table 3). No significant differences in insulin sensitivity, measured by the homeostasis model assessment model, were found (Table 4).

\section{Discussion}

In the present study, we did not detect any immediate impact on postprandial lipaemia by an amount of exercise that we estimated realistic in daily living for semi-sedentary

Table 2. Incremental areas under the curve (iAUC) of glucose, insulin and lipids following a test meal in twelve type 2 diabetic men for each of the protocols*

(Mean values and standard deviations)

\begin{tabular}{|c|c|c|c|c|c|c|c|}
\hline & \multicolumn{2}{|c|}{ Protocol A } & \multicolumn{2}{|c|}{ Protocol B } & \multicolumn{2}{|c|}{ Protocol C } & \multirow{2}{*}{$\begin{array}{c}P \text { value } \\
\text { (comparisons between protocols) }\end{array}$} \\
\hline & Mean & SD & Mean & SD & Mean & SD & \\
\hline ¡AUC glucose $(\mathrm{mmol} / \mathrm{l} \times 480 \mathrm{~min})$ & 202 & 535 & 73 & 555 & 74 & 609 & 0.42 \\
\hline iAUC insulin (pmol/l $\times 480 \mathrm{~min})$ & 31563 & 17079 & 28640 & 19417 & 34513 & 21626 & 0.56 \\
\hline ¡AUC triacylglycerol $(\mathrm{mmol} / \mathrm{I} \times 480 \mathrm{~min})$ & 541 & 332 & 589 & 537 & 650 & 443 & 0.21 \\
\hline iAUC fatty acids $(\mathrm{mmol} / \mathrm{l} \times 480 \mathrm{~min})$ & -75 & 94 & -69 & 92 & -67 & 96 & 0.85 \\
\hline iAUC cholesterol $(\mathrm{mmol} / / \mathrm{l} \times 480 \mathrm{~min})$ & -77 & 72 & -20 & 89 & -24 & 115 & 0.07 \\
\hline iAUC HDL-cholesterol $(\mathrm{mmol} / \mathrm{l} \times 480 \mathrm{~min})$ & -83 & 84 & 9 & 134 & -32 & 89 & 0.08 \\
\hline
\end{tabular}

* Test meal consisted of soup plus carbohydrate $(50 \mathrm{~g})$ plus alcohol $(40 \mathrm{~g})$ plus butter $(100 \mathrm{~g})$. In protocol A, participants did not exercise; in protocol B, participants rested the day before the meal test and exercised for $40 \mathrm{~min}$ at $40 \% \mathrm{~V}_{\mathrm{O} 2 \mathrm{max}}$ on the day of the meal test; in protocol $\mathrm{C}$, participants exercised for $40 \mathrm{~min}$ at $40 \%$ $\mathrm{V}_{\mathrm{O} 2 \mathrm{max}}$ the day before the meal test.

Table 3. Areas under the curve (AUC) of glucose, insulin and lipids following a test meal in twelve type 2 diabetic men for each of the protocols*

(Mean values and standard deviations)

\begin{tabular}{|c|c|c|c|c|c|c|c|}
\hline & \multicolumn{2}{|c|}{ Protocol A } & \multicolumn{2}{|c|}{ Protocol B } & \multicolumn{2}{|c|}{ Protocol C } & \multirow{2}{*}{$\begin{array}{c}P \text { value } \\
\text { (comparisons between protocols) }\end{array}$} \\
\hline & Mean & SD & Mean & SD & Mean & SD & \\
\hline AUC glucose $(\mathrm{mmol} / \mathrm{l} \times 480 \mathrm{~min})$ & 4658 & 1432 & 4347 & 1170 & 4493 & 1183 & 0.2 \\
\hline AUC insulin (pmol/l $\times 480 \mathrm{~min})$ & $51518^{\mathrm{a}}$ & 31204 & $50320^{\mathrm{a}}$ & 35736 & $58233^{\mathrm{b}}$ & 42865 & 0.03 \\
\hline AUC triacylglycerol $(\mathrm{mmol} / \mathrm{l} \times 480 \mathrm{~min})$ & 1803 & 1023 & 1741 & 1261 & 1932 & 1595 & 0.72 \\
\hline AUC fatty acids $(\mathrm{mmol} / / \mathrm{l} \times 480 \mathrm{~min})$ & 267 & 76 & 252 & 66 & 257 & 88 & 0.52 \\
\hline AUC cholesterol (mmol/l × $480 \mathrm{~min})$ & 2783 & 480 & 2726 & 340 & 2830 & 480 & 0.72 \\
\hline AUC HDL-cholesterol $(\mathrm{mmol} / \mathrm{I} \times 480 \mathrm{~min})$ & 432 & 117 & 433 & 103 & 435 & 102 & 0.37 \\
\hline
\end{tabular}

a,b Mean values within a row with unlike superscript letters were significantly different $(P=0.03)$.

* Test meal consisted of soup plus carbohydrate $(50 \mathrm{~g})$ plus alcohol $(40 \mathrm{~g})$ plus butter $(100 \mathrm{~g})$. In protocol A, participants did not exercise; in protocol B, participants rested the day before the meal test and exercised for $40 \mathrm{~min}$ at $40 \% \mathrm{~V}_{\mathrm{O} 2 \mathrm{max}}$ on the day of the meal test; in protocol C, participants exercised for 40 min at $40 \%$ $\mathrm{V}_{\mathrm{O} 2 \mathrm{max}}$ the day before the meal test. 

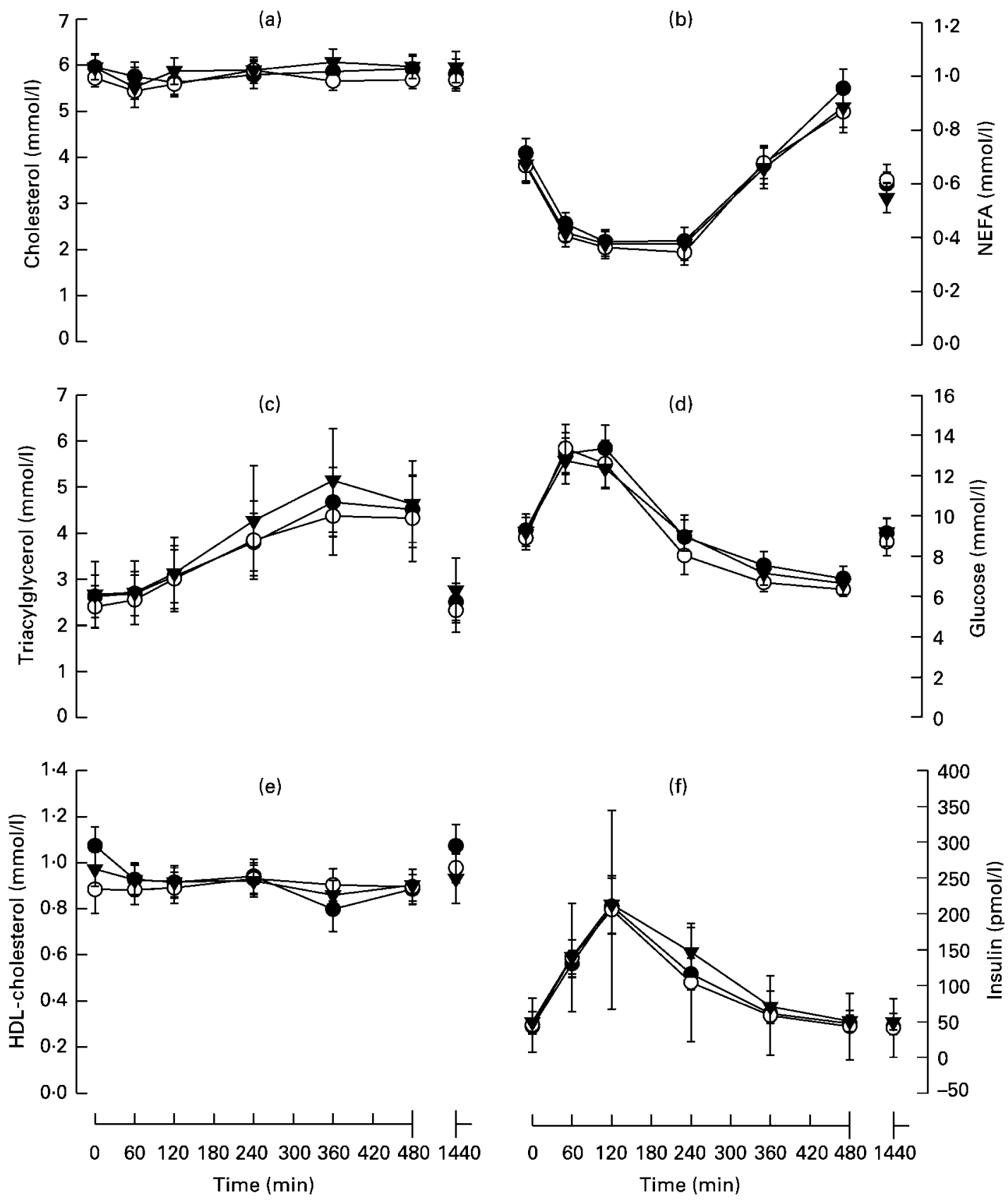

Fig. 2. Serum postprandial cholesterol (a), NEFA (b), triacylglycerols (c), plasma glucose (d), HDL-cholesterol (e) and insulin (f) in twelve type 2 diabetic men following a meal of soup with $100 \mathrm{~g}$ butter plus $40 \mathrm{~g}$ alcohol plus $50 \mathrm{~g}$ carbohydrate. Protocol $\mathrm{A}(\bullet)$ participants did not exercise. Protocol $\mathrm{B}(\mathrm{O})$ participants rested the day before the meal test and exercised for $40 \mathrm{~min}$ at $40 \% \mathrm{~V}_{\mathrm{O} \max }$ on the day of the meal test. Protocol $\mathrm{C}(\boldsymbol{\nabla})$ participants exercised for $40 \mathrm{~min}$ at $40 \% \mathrm{~V}_{\mathrm{O} 2 \max }$ the day before the meal test and rested during the meal test. Values are means, with standard errors of the mean represented by vertical bars.

type 2 diabetic men. This contrasts with previous studies on exercise and postprandial lipaemia in healthy subjects (Tsetsonis \& Hardman, 1996; Gill et al. 2001). In the latter studies, however, a much higher exercise intensity and duration was chosen than in the present study. We decided to examine a less intensive exercise since largescale epidemiological studies have shown that light and moderate daily exercise have a striking effect on the risk of CVD (Hu et al. 2001), and of type 2 diabetes (Hu et al. 2003). According to the present acute study, with all its limitations, the cardioprotective effect of light exercise seems not to be mediated through a reduction in postprandial lipaemia. To be able to separate the effects of alcohol and exercise, studies using a similar amount of exercise on a meal test without alcohol should have been carried out. Although Danes do not habitually consume $40 \mathrm{~g}$ alcohol in the morning, it is quite common on festive occasions.

In the Insulin Resistance Atherosclerosis Study, physical activity was found to be positively associated with increased insulin sensitivity (Mayer-Davis et al. 1998) and one single bout of glycogen-depleting exercise in type 2 diabetic patients increased the non-oxidative glucose 
Table 4. Insulin resistance using the homeostasis model assessment (HOMA) following a test meal in twelve type 2 diabetic men for each of the protocols*

(Mean values and standard deviations)

\begin{tabular}{|c|c|c|c|c|c|c|c|}
\hline & \multicolumn{2}{|c|}{ Protocol A } & \multicolumn{2}{|c|}{ Protocol B } & \multicolumn{2}{|c|}{ Protocol C } & \multirow{2}{*}{$\begin{array}{c}P \text { value } \\
\text { (difference between protocols) }\end{array}$} \\
\hline & Mean & SD & Mean & SD & Mean & SD & \\
\hline $\mathrm{HOMA}, \mathrm{T}=0 \mathrm{~min}$ & 2.9 & $2 \cdot 3$ & 3 & $2 \cdot 4$ & $3 \cdot 2$ & 3.4 & 0.98 \\
\hline $\mathrm{HOMA}, \mathrm{T}=1440 \mathrm{~min}$ & $2 \cdot 8$ & $2 \cdot 3$ & $2 \cdot 6$ & $2 \cdot 6$ & $3 \cdot 2$ & $2 \cdot 6$ & 0.08 \\
\hline
\end{tabular}

* Test meal consisted of soup plus carbohydrate $(50 \mathrm{~g})$ plus alcohol $(40 \mathrm{~g})$ plus butter $(100 \mathrm{~g})$. In protocol A, participants did not exercise; in protocol B, participants rested the day before the meal test and exercised for $40 \mathrm{~min}$ at $40 \% \mathrm{~V}_{\mathrm{O} \text { max }}$ on the day of the meal test; in protocol $\mathrm{C}$, participants exercised for $40 \mathrm{~min}$ at $40 \% \mathrm{~V}_{\mathrm{O} 2 \max }$ the day before the meal test. HOMA was calculated as mean (fasting insulin $(\mu \mathrm{U} / \mathrm{ml}) \times$ fasting glucose $\left.(\mathrm{mmol} / \mathrm{l})\right) / 22.5$.

disposal for $16 \mathrm{~h}$ as measured by the insulin clamp technique (Devlin et al. 1987). The present study did not show any effect on insulin sensitivity, measured by the homeostasis model assessment model.

AUC for insulin were higher in protocol C; however, the higher basal insulin levels in protocol $\mathrm{C}$ as compared with protocols $\mathrm{A}$ and $\mathrm{B}$ may explain this. Thus, when adjusted for basal levels, the iAUC did not differ between the three protocols.

Exercise for $45 \mathrm{~min}$ at $53 \% \mathrm{~V}_{\mathrm{O} 2 \max }$ carried out $45 \mathrm{~min}$ after a mixed meal significantly reduced the $4 \mathrm{~h}$ postprandial AUC for glucose and insulin in type 2 diabetic patients (Larsen et al. 1997). The explanation might be that their patients consumed a carbohydrate-rich meal and exercised $45 \mathrm{~min}$ after breakfast, when glucose and insulin levels were increasing, whereas our participants consumed a high-fat meal and exercised $3.5 \mathrm{~h}$ after the meal, when glucose and insulin levels were decreasing, and most of the ingested triacylglycerol was absorbed. It could be that exercising 45 min rather than $3.5 \mathrm{~h}$ after a meal more effectively reduces the postprandial glucose responses. There were two reasons for exercising our participants after $3.5 \mathrm{~h}$. First, we wanted the blood ethanol to reach a level where the participants could cooperate properly in the exercise session. Second, we wanted a postprandial absorption that was similar for meal tests with and without exercise. Some studies have shown that moderate exercise increases gastric emptying (Moore et al. 1990), probably due to increased gastric blood flow.

It has been argued that abnormal NEFA metabolism is essential for the insulin resistance syndrome (McGarry, 2002). In lean type 2 diabetic patients (Groop et al. 1989), impairment of both the insulin suppression of NEFA and the turnover of NEFA was found as compared with ageand weight-matched controls.

We did not detect any differences in NEFA. In contrast, Rasmussen et al. (1999) found that the NEFA levels in type 2 diabetic patients were reduced by $30 \mathrm{~min}$ exercise at $40 \%$ $\mathrm{V}_{\mathrm{O} 2 \mathrm{max}} 30 \mathrm{~min}$ after a test meal with alcohol compared with a sedentary day without alcohol. Previously, we have found that $40 \mathrm{~g}$ ethanol is a suppressor of NEFA in type 2 diabetic patients (Dalgaard et al. 2004). The difference in both the timing of the exercise and the fact that the participants in the present study ingested ethanol on all meal tests may explain the contrasting results to the study of Rasmussen et al. (1999).

Regular alcohol consumption in moderate doses is associated with improved insulin sensitivity in non-diabetic subjects (Kiechl et al. 1996; Lazarus et al. 1997; Flanagan et al. 2000). Evidence is conflicting regarding alcohol and insulin sensitivity in those with type 2 diabetes. Insulin sensitivity did not change in type 2 diabetic patients in response to ethanol given intravenously (Christiansen et al. 1996) whereas the oral intake of 12 and $24 \mathrm{~g}$ alcohol with carbohydrate pointed to an alcohol-induced aggravation of insulin resistance (Christiansen et al. 1993). It is possible that the amount of alcohol in the present study induced enhanced insulin resistance in the postprandial phase, counteracting the effect of exercise on the postprandial lipaemia. No significant effect of low-intensity exercise on postprandial lipaemia following a fat-rich meal with alcohol was seen in the middle-aged type 2 diabetic men.

Lifestyle intervention programmes have shown that both a moderate intake of alcohol and exercise have beneficial effects on the risk of developing type 2 diabetes and CVD. Evaluation of the long-term effects of regular alcohol drinking and graded exercise load on the postprandial lipaemia in type 2 diabetic individuals needs further investigation.

\section{Acknowledgements}

We thank Kirsten Eriksen and Tove Skrumsager for excellent technical assistance, and Eva Pedersen for dietetic assistance. The present study was supported by grants from the Danish Diabetes Association, Eli Lilly Diabetes Research Foundation, The Danish Medical Research Council, The Institute of Clinical Experimental Research, Aarhus University, and Novo Nordisk Foundation.

\section{References}

Andersen L, Dinesen B, Jorgensen PN, Poulsen F \& Roder ME (1993) Enzyme immunoassay for intact human insulin in serum or plasma. Clin Chem 39, 578-582.

Andersen LB, Schnohr P, Schroll M \& Hein HO (2000) All-cause mortality associated with physical activity during leisure time, work, sports, and cycling to work. Arch Intern Med 160, $1621-1628$.

Åstrand I (1960) Aerobic work capacity in men and women with special reference to age. Acta Physiol Scand 49, 49-92.

Berntorp K, Eriksson KF \& Lindgarde F (1986) The importance of diabetes heredity in lean subjects on insulin secretion, blood lipids and oxygen uptake in the pathogenesis of glucose intolerance. Diabetes Res 3, 231-236.

Boquist S, Ruotolo G, Tang R, Bjorkegren J, Bond MG, de Faire 
U, Karpe F \& Hamsten A (1999) Alimentary lipemia, postprandial triglyceride-rich lipoproteins, and common carotid intimamedia thickness in healthy, middle-aged men. Circulation 100, 723-728.

Chen YD, Swami S, Skowronski R, Coulston A \& Reaven GM (1993) Differences in postprandial lipemia between patients with normal glucose tolerance and noninsulin-dependent diabetes mellitus. J Clin Endocrinol Metab 76, 172-177.

Christiansen C, Thomsen C, Rasmussen O, Glerup H, Berthelsen J, Hansen C, Orskov H \& Hermansen K (1993) Acute effects of graded alcohol intake on glucose, insulin and free fatty acid levels in non-insulin-dependent diabetic subjects. Eur J Clin Nutr 47, 648-652.

Christiansen C, Thomsen C, Rasmussen O, Hansen C \& Hermansen K (1996) The acute impact of ethanol on glucose, insulin, triacylglycerol, and free fatty acid responses and insulin sensitivity in type 2 diabetes. Br J Nutr 76, 669-675.

Conigrave KM, Hu BF, Camargo CA Jr, Stampfer MJ, Willett WC \& Rimm EB (2001) A prospective study of drinking patterns in relation to risk of type 2 diabetes among men. Diabetes 50, 2390-2395.

Dalgaard M, Thomsen C, Rasmussen BM, Holst JJ \& Hermansen K (2004) Ethanol with a mixed meal decreases the incretin levels early postprandially and increases postprandial lipemia in type 2 diabetic patients. Metabolism 53, 77-83.

Devlin JT, Hirshman M, Horton ED \& Horton ES (1987) Enhanced peripheral and splanchnic insulin sensitivity in NIDDM men after single bout of exercise. Diabetes 36, 434-439.

El Sayed MS \& AL-Bayatti MF (2001) Effects of alcohol ingestion following exercise on postprandial lipemia. Alcohol 23, $15-21$.

Fielding BA, Reid G, Grady M, Humphreys SM, Evans K \& Frayn KN (2000) Ethanol with a mixed meal increases postprandial triacylglycerol but decreases postprandial non-esterified fatty acid concentrations. Br J Nutr 83, 597-604.

Flanagan DE, Moore VM, Godsland IF, Cockington RA, Robinson JS \& Phillips DI (2000) Alcohol consumption and insulin resistance in young adults. Eur J Clin Invest 30, 297-301.

Fraze E, Donner CC, Swislocki AL, Chiou YA, Chen YD \& Reaven GM (1985) Ambient plasma free fatty acid concentrations in noninsulin-dependent diabetes mellitus: evidence for insulin resistance. J Clin Endocrinol Metab 61, 807-811.

Gill JM, Herd SL \& Hardman AE (2002) Moderate exercise and post-prandial metabolism: issues of dose-response. J Sports Sci 20, 961-967.

Gill JM, Mees GP, Frayn KN \& Hardman AE (2001) Moderate exercise, postprandial lipaemia and triacylglycerol clearance. Eur J Clin Invest 31, 201-207.

Groop LC, Bonadonna RC, DelPrato S, Ratheiser K, Zyck K, Ferrannini E \& DeFronzo RA (1989) Glucose and free fatty acid metabolism in non-insulin-dependent diabetes mellitus. Evidence for multiple sites of insulin resistance. J Clin Invest 84, 205-213.

Haffner SM, Kennedy E, Gonzalez C, Stern MP \& Miettinen H (1996) A prospective analysis of the HOMA model. The Mexico City Diabetes Study. Diabetes Care 19, 1138-1141.

Hartung GH, Lawrence SJ, Reeves RS \& Foreyt JP (1993) Effect of alcohol and exercise on postprandial lipemia and triglyceride clearance in men. Atherosclerosis 100, 33-40.

Hendriks HF, Veenstra J, van Tol A, Groener JE \& Schaafsma G (1998) Moderate doses of alcoholic beverages with dinner and postprandial high density lipoprotein composition. Alcohol Alcohol 33, 403-410.

Hu FB, Stampfer MJ, Solomon C, Liu S, Colditz GA, Speizer FE, Willett WC \& Manson JE (2001) Physical activity and risk for cardiovascular events in diabetic women. Ann Intern Med $\mathbf{1 3 4}$ 96-105.

Hu G, Qiao Q, Silventoinen K, Eriksson JG, Jousilahti P, Lindstrom J, Valle TT, Nissinen A \& Tuomilehto J (2003) Occupational, commuting, and leisure-time physical activity in relation to risk for Type 2 diabetes in middle-aged Finnish men and women. Diabetologia 46, 322-329.

Isomaa B, Almgren P, Tuomi T, Forsen B, Lahti K, Nissen M, Taskinen MR \& Groop L (2001) Cardiovascular morbidity and mortality associated with the metabolic syndrome. Diabetes Care 24, 683-689.

Karpe F (1999) Postprandial lipoprotein metabolism and atherosclerosis. J Intern Med 246, 341-355.

Kiechl S, Willeit J, Poewe W, Egger G, Oberhollenzer F, Muggeo M \& Bonora E (1996) Insulin sensitivity and regular alcohol consumption: large, prospective, cross sectional population study (Bruneck study). BMJ 313, 1040-1044.

Larsen JJ, Dela F, Kjaer M \& Galbo H (1997) The effect of moderate exercise on postprandial glucose homeostasis in NIDDM patients. Diabetologia 40, 447-453.

Lazarus R, Sparrow D \& Weiss ST (1997) Alcohol intake and insulin levels. The Normative Aging Study. Am J Epidemiol 145, 909-916.

Lindgarde F \& Saltin B (1981) Daily physical activity, work capacity and glucose tolerance in lean and obese normoglycaemic middle-aged men. Diabetologia 20, 134-138.

McGarry JD (2002) Banting Lecture 2001: dysregulation of fatty acid metabolism in the etiology of type 2 diabetes. Diabetes $\mathbf{5 1}$, $7-18$.

Malmstrom R, Packard CJ, Caslake M, Bedford D, Stewart P, Yki-Jarvinen H, Shepherd J \& Taskinen MR (1997) Defective regulation of triglyceride metabolism by insulin in the liver in NIDDM. Diabetologia 40, 454-462.

Matthews DR, Hosker JP, Rudenski AS, Naylor BA, Treacher DF \& Turner RC (1985) Homeostasis model assessment: insulin resistance and beta-cell function from fasting plasma glucose and insulin concentrations in man. Diabetologia 28, 412-419.

Mayer-Davis EJ, D'Agostino R Jr, Karter AJ, Haffner SM, Rewers MJ, Saad M \& Bergman RN (1998) Intensity and amount of physical activity in relation to insulin sensitivity: the Insulin Resistance Atherosclerosis Study. JAMA 279, 669-674.

Moore JG, Datz FL \& Christian PE (1990) Exercise increases solid meal gastric emptying rates in men. Dig Dis Sci $\mathbf{3 5}$, $428-432$.

Mukamal KJ, Conigrave KM, Mittleman MA, Camargo CA Jr, Stampfer MJ, Willett WC \& Rimm EB (2003) Roles of drinking pattern and type of alcohol consumed in coronary heart disease in men. $N$ Engl J Med 348, 109-118.

Parks EJ (2001) Recent findings in the study of postprandial lipemia. Curr Atheroscler Rep 3, 462-470.

Patsch JR, Miesenbock G, Hopferwieser T, Muhlberger V, Knapp E, Dunn JK, Gotto AM Jr \& Patsch W (1992) Relation of triglyceride metabolism and coronary artery disease. Studies in the postprandial state. Arterioscler Thromb 12, 1336-1345.

Pellett PL (1990) Food energy requirements in humans. Am J Clin Nutr 51, 711-722.

Petitt DS, Arngrimsson SA \& Cureton KJ (2003) Effect of resistance exercise on postprandial lipemia. J Appl Physiol 94, 694-700.

Petitt DS \& Cureton KJ (2003) Effects of prior exercise on postprandial lipemia: a quantitative review. Metabolism 52, 418-424.

Pownall HJ (1994) Dietary ethanol is associated with reduced lipolysis of intestinally derived lipoproteins. J Lipid Res 35, $2105-2113$.

Rasmussen BM, Christiansen C, Rasmussen OW, Hansen C \& 
Hermansen K (1999) Alcohol and postexercise metabolic responses in type 2 diabetes. Metabolism 48, 597-602.

Ryu JE, Howard G, Craven TE, Bond MG, Hagaman AP \& Crouse JR III (1992) Postprandial triglyceridemia and carotid atherosclerosis in middle-aged subjects. Stroke 23, 823-828.

Schlierf G, Dinsenbacher A, Kather H, Kohlmeier M \& Haberbosch W (1987) Mitigation of alimentary lipemia by postprandial exercise - phenomena and mechanisms. Metabolism 36, 726-730.

Sharrett AR, Heiss G, Chambless LE, Boerwinkle E, Coady SA, Folsom AR \& Patsch W (2001) Metabolic and lifestyle determinants of postprandial lipemia differ from those of fasting triglycerides: The Atherosclerosis Risk In Communities (ARIC) study. Arterioscler Thromb Vasc Biol 21, 275-281.

Suter PM, Gerritsen-Zehnder M, Hasler E, Gurtler M, Vetter W \& Hanseler E (2001) Effect of alcohol on postprandial lipemia with and without preprandial exercise. J Am Coll Nutr 20, $58-64$.

Tanasescu M, Hu FB, Willett WC, Stampfer MJ \& Rimm EB (2001) Alcohol consumption and risk of coronary heart disease among men with type 2 diabetes mellitus. J Am Coll Cardiol 38, $1836-1842$.

Taskinen MR (2003) Diabetic dyslipidaemia: from basic research to clinical practice. Diabetologia 46, 733-749.

Thomsen C, Storm H, Holst JJ \& Hermansen K (2003)
Differential effects of saturated and monounsaturated fats on postprandial lipemia and glucagon-like peptide 1 responses in patients with type 2 diabetes. Am J Clin Nutr 77, 605-611.

Trinder P (1969) Determination of glucose in blood using glucose oxidase with an alternative oxygen acceptor. Ann Clin Biochem 6, 24-27.

Tsetsonis NV \& Hardman AE (1996) Reduction in postprandial lipemia after walking: influence of exercise intensity. Med Sci Sports Exerc 28, 1235-1242.

Tsetsonis NV, Hardman AE \& Mastana SS (1997) Acute effects of exercise on postprandial lipemia: a comparative study in trained and untrained middle-aged women. Am J Clin Nutr 65, 525-533.

van Tol A, Groener JE, Scheek LM, van Gent T, Veenstra J, van de Pol H, Hendriks HF \& Schaafsma G (1995) Induction of net mass lipid transfer reactions in plasma by wine consumption with dinner. Eur J Clin Invest 25, 390-395.

Veenstra J, Ockhuizen T, van de Pol H, Wedel M \& Schaafsma G (1990) Effects of a moderate dose of alcohol on blood lipids and lipoproteins postprandially and in the fasting state. Alcohol Alcohol 25, 371-377.

Wei M, Gibbons LW, Kampert JB, Nichaman MZ \& Blair SN (2000) Low cardiorespiratory fitness and physical inactivity as predictors of mortality in men with type 2 diabetes. Ann Intern Med 132, 605-611. 